\title{
Influência da Idade de Desmama e de Início do Fornecimento do Volumoso a Bezerros sobre a Digestibilidade de Nutrientes e o Balanço de Nitrogênio, Pós-desmama ${ }^{1}$
}

\section{Evandro de Oliveira Rocha ${ }^{2}$, Carlos Augusto de Alencar Fontes ${ }^{3}$, Mário Fonseca Paulino ${ }^{4}$, José Carlos Pereira ${ }^{4}$, Márcio Machado Ladeira ${ }^{5}$}

\begin{abstract}
RESUMO - O objetivo deste trabalho foi estudar os efeitos da idade ao início do fornecimento de volumoso (4 ou 60 dias) e idade da desmama (35 ou 56 dias) sobre a digestibilidade da matéria seca (MS), proteína bruta (PB), fibra em detergente neutro (FDN) e energia bruta (EB) e o balanço de nitrogênio no período pós-desmama, em bezerros machos holandeses e mestiços Holandês x Zebu. Os animais foram alojados em gaiolas de metabolismo para coleta de fezes e urina. Uma ração única, fornecida ad libitum, contendo 33,0\% de volumoso, $67,0 \%$ de concentrado e $16 \%$ de proteína na MS foi usada. O tratamento prévio não influenciou os coeficientes de digestibilidade aparente da MS, PB, FDN e EB e o balanço de nitrogênio, quando avaliados no período de 72 a 78 dias de idade.
\end{abstract}

Palavras-chave: balanço de nitrogênio, bezerros, concentrado, digestibilidade, volumoso

\section{Influence of Weaning Age and the Beginning of Forage Supply to Calves on the Nutrient Digestibility and Nitrogen Balance, Post Weaning}

\begin{abstract}
The objective of this work was to study the effects of age at the beginning of forage supply ( 4 or 60 days) and weaning age (35 or 56 days) on the digestibility of dry matter (DM), crude protein (CP), neutral detergent fiber (NDF) and gross energy (GE) and nitrogen balance, in the post weaning period, in Holstein and Holstein x Zebu crossbred bull calves. The animals were maintained in metabolism cages for feces and urine collection. A unique diet containing $33.0 \%$ of forage, $67.0 \%$ of concentrate and $16 \%$ of crude protein on DM basis was used. The previous treatment did not affect the apparent digestibility coefficients of DM, CP, NDF and GE, and nitrogen balance, when evaluated in the period from 72 to 78 days of age.
\end{abstract}

Key Words: nitrogen balance, calves, concentrate, digestibility, forage

\section{Introdução}

A criação de bezerros eleva o custo da produção de leite, especialmente quando o leite integral é fornecido por períodos longos, ao invés de destinar-se ao consumo humano e transformar-se em receita. $\mathrm{Na}$ tentativa de reduzir os custos, bezerros machos são geralmente sacrificados ao nascer, principalmente os de maior predominância de sangue europeu, pois, apesar de terem bom potencial para ganho de peso, não conseguem se adaptar às condições rústicas de criação mais extensiva. Desta forma, é eliminada, precocemente, uma fonte de alimento de alto valor nutritivo para o homem.

Torna-se necessário encontrar alternativas econômicas que permitam ao fazendeiro a criação mais eficiente de bezerros.
O trato digestivo dos bezerros ao nascer assemelha-se fisiologicamente ao dos monogástricos. Nessa fase, o alimento básico é a dieta líquida, sendo a atividade gástrica digestiva exercida pelo abomaso. É a fase mais crítica do ponto de vista nutricional, pois, devido a limitações enzimáticas e à ausência de síntese microbiana, os bezerros têm exigências dietéticas mais complexas, quanto a aminoácidos e vitaminas, e não utilizam com eficiência determinadas fontes protéicas e energéticas. $\mathrm{O}$ rúmen tem pequena importância na nutrição do bezerro que recebe o leite como seu único alimento. O rúmen funcional é garantia de animal mais rústico, menos sujeito a diarréias e capaz de aproveitar alimentos mais grosseiros, embora com menor eficiência de utilização de alimentos concentrados que os monogástricos.

O tipo de alimentação ao qual o bezerro é submetido

\footnotetext{
${ }^{1}$ Parte da Tese de Doutorado do primeiro autor apresentada à UFV, parcialmente financiada pelo CNPq.

2 Doutor em Zootecnia, DZO/UFV, Viçosa, MG.

${ }^{3}$ Pesquisador Titular do LZNA, CCTA, UENF, Campos dos Goytacazes, RJ.

${ }^{4}$ Professor do Departamento de Zootecnia, DZO/UFV, Viçosa, MG.

${ }^{5}$ Estudante de Doutorado/UFMG.
} 
tem grande influência na transição do estado de monogástrico para poligástrico, verificando-se que dietas líquidas retardam e os alimentos sólidos (volumosos e concentrados) abreviam o fenômeno. BLAXTER et al. (1952) observaram marcado aumento no volume dos três primeiros compartimentos do estômago (rúmen, retículo e omaso) de bezerros que receberam feno, além do leite. Além disso, o feno propicia o desenvolvimento de microflora ruminal típica e eleva o $\mathrm{pH}$, provavelmente em virtude da maior produção de saliva, provocada pela remastigação (LUCCI, 1976).

Pesquisando o desenvolvimento microbiano ruminal, em bezerros desmamados com quatro e com seis semanas de idade, ANDERSON et al. (1987b) verificaram nos primeiros maior atividade microbiana ruminal.

Embora o rúmen tenha habilidade inata para se desenvolver, a alimentação dos bezerros apenas com dieta líquida reduz grandemente sua taxa de desenvolvimento, ocorrendo retardamento do crescimento papilar, na ausência de ração sólida, e redução da concentração ruminal de ácidos graxos voláteis (ANDERSON et al., 1987a; MISRA e MEHRA, 1993). Além disso, o consumo precoce de ração tem os efeitos benéficos de acelerar a motilidade e o desenvolvimento muscular do rúmen e produção e absorção de AGV (OTTERBY e LINN, 1981; TAMATE et al., 1962; e WILLIAMS et al., 1985).

Há alguns anos, pesquisadores, particularmente nos Estados Unidos, têm investigando a possibilidade de bezerros, em aleitamento artificial, receberem volumoso somente a partir de idade mais avançada (60 dias), como forma de estimular o consumo de concentrado, contrariando o princípio tradicional de se fornecer esse alimento desde o início de vida dos animais. Para que isto seja possível, é necessário, entretanto, que se forneça concentrado inicial rico em fibra, atendendo às necessidades fisiológicas dos animais e evitando distúrbios como paraqueratose e timpanismo, característicos de bezerros que recebem concentrado em altas proporções. Deve-se, entretanto, avaliar se essa prática acarreta alterações no desenvolvimento ruminal e, conseqüentemente, na digestibilidade dos vários nutrientes das rações para bezerros jovens.

O experimento foi conduzido com o objetivo de estudar os efeitos da idade ao início de fornecimento de volumoso (4 ou 60 dias) e idade da desmama ( 35 ou 56 dias) sobre a digestibilidade da MS, PB, FDN e EB e o balanço de nitrogênio.

\section{Material e Métodos}

Foram utilizados dezesseis bezerros, anteriormente submetidos a experimento compreendendo quatro tratamentos, envolvendo a combinação de duas idades de desmama ( 35 ou 56 dias) e duas idades de início de fornecimento de volumoso (4 ou 60 dias), num arranjo fatorial. $\mathrm{O}$ ensaio foi conduzido em galpão fechado tendo os bezerros permanecido em gaiolas metálicas individuais providas de estrado e fundo para coleta de urina, que era recolhida em baldes plásticos contendo $\mathrm{HCl}$ na proporção 1:1 em água. Para a coleta de fezes, foram adaptados arreios de couro, aos animais, providos de coletores de fezes.

Foi utilizada a mesma ração concentrada utilizada no período de aleitamento, usando-se o capim-napier (Pennisetum purpureum, Schum) como alimento volumoso. A proporção volumoso: concentrado foi de 1:2 (base da MS), semelhante à proporção média consumida, na fase final do período de aleitamento, pelos animais que recebiam o volumoso e concentrado à vontade, em cochos separados.

As composições químico-bromatológicas médias do capim-napier e do concentrado, os quais foram fornecidos misturados a partir do $60^{\circ}$ dia de idade, na proporção anteriormente referida, são mostradas na Tabela 1.

$O$ período de adaptação às instalações teve duração de 12 dias, fornecendo-se o alimento à vontade. A seguir, iniciou-se o período de coleta, no qual o alimento foi fornecido, a cada bezerro, em quantidade $5 \%$ superior ao consumo médio individual observado nos cinco últimos dias do período de adaptação, mantendo-se constante a proporção de volumoso: concentrado.

O período de coleta, para cada animal, teve duração de sete dias, sendo retiradas amostras diárias do volumoso e concentrado fornecidos, bem como amostras individuais, correspondentes a $10 \%$ do total, das sobras, fezes e urina, as quais foram acondicionadas em sacos plásticos, congeladas e armazenadas a $-15^{\circ} \mathrm{C}$ para análises químicas posteriores.

Foram determinados os coeficientes de digestibilidade aparentes da matéria seca (MS), proteína bruta (PB), fibra em detergente neutro (FDN) e energia bruta $(\mathrm{EB})$, além do balanço de nitrogênio (BN), com base nas composições e quantidades de matéria seca do alimento oferecido, das sobras e fezes, além do volume e teor de nitrogênio da urina.

Para o cálculo dos coeficientes de digestibilidade 
aparentes (CDap), utilizou-se a fórmula:

CDap $=$ Nutriente ingerido $(\mathrm{kg})$ - nutriente nas fezes $(\mathrm{kg}) \times 100$, nutriente ingerido $(\mathrm{kg})$

Para o cálculo do balanço diário de nitrogênio $(\mathrm{BN})$, utilizou-se a seguinte fórmula:

$\mathrm{BN}=\mathrm{N}$ ingerido $(\mathrm{g})-\mathrm{N}$ nas fezes $(\mathrm{g})-\mathrm{N}$ na urina $(\mathrm{g})$.

$\mathrm{O}$ consumo de energia metabolizável (EM) foi estimado utilizando-se o fator 0,82 para conversão de energia digestível em metabolizável.

As análises estatísticas foram realizadas utili-

Tabela 1 - Composição químico-bromatológica do capimnapier e do concentrado fornecidos (base da MS) ${ }^{1}$

Table 1- Composition of the napier grass and of the concentrate fed to calves (dry matter basis) ${ }^{1}$

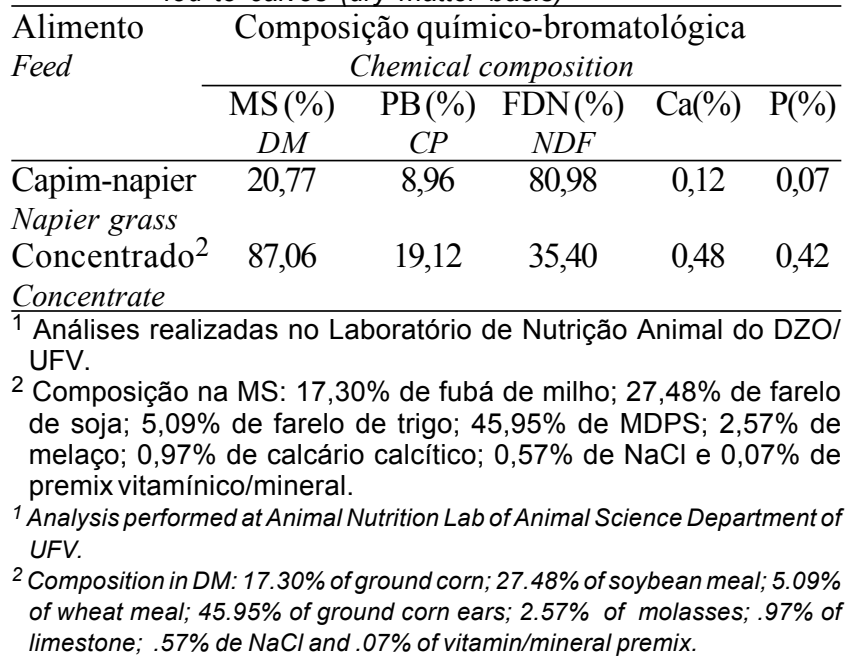

zando-se o programa LSMLMW (Least Squares and Maximum Likelihood Mixed Model), versão PC-1 (HARVEY, 1990), e o teste de Newman Keuls a 5\% de probabilidade, para comparação entre médias dos tratamentos.

O delineamento utilizado foi inteiramente casualizado, efetuando-se as análises de variância segundo o modelo:

em que

$$
Y_{i j}=\mu+T_{i}+e_{i j}
$$

$Y_{i j}=$ observação referente ao animal j, submetido ao tratamento prévio i;

$\mu=$ média geral;

$\mathrm{T}_{\mathrm{i}}=$ efeito do tratamento prévio $\mathrm{i}$, em que $\mathrm{i}=1,2$, 3 e 4, sendo $1=$ volumoso aos 4 dias e desmama aos 56 dias; $2=$ volumoso aos 60 dias e desmama aos 56 dias; $3=$ volumoso aos 4 dias e desmama aos 35 dias e 4= volumoso aos 60 dias e desmama aos 35 dias; e

$\mathrm{e}_{\mathrm{ijk}}=$ erro aleatório, pressuposto normalmente distribuído, com média igual a zero e variância $\sigma^{2}$.

\section{Resultados e Discussão}

A Tabela 2 mostra as médias de quadrados mínimos para consumo diário de matéria seca (MS), proteína bruta (PB), fibra em detergente neutro (FDN) e energia metabolizável (EM) dos bezerros, durante o ensaio de digestibilidade ( 72 a 78 dias de idade). $\mathrm{Na}$ Tabela 3 encontram-se os coeficientes de

Tabela 2 -Médias de quadrados mínimos para consumo diário de matéria seca (MS), proteína bruta (PB), fibra em detergente neutro (FDN) e energia metabolizável (EM) dos bezerros, durante o ensaio de digestibilidade (72 a 78 dias de idade), segundo o tratamento prévio

Table 2- Least square means for daily intake of dry matter (DM), crude protein (CP), neutral detergent fiber (NDF), metabolizable energy (ME) of calves, during the digestibility trial (from 72 to 78 days of age), according to previous treatment

\begin{tabular}{l}
$\begin{array}{l}\text { Tratamento } \\
\text { Treatment }\end{array}{ }^{1}$ \\
\cline { 2 - 4 }
\end{tabular}


Tabela 3 - Médias de quadrados mínimos para coeficientes de digestibilidade aparente (CDA) de nutrientes, para os bezerros, de acordo com o tratamento prévio

Table 3 - Least square means for the apparent digestibility coefficients $(A D C)$ of nutrients for calves according to previous treatment

\begin{tabular}{lcccc} 
Tratamento $^{1}$ & \multicolumn{4}{c}{ CDA (\%) } \\
Treatment & \multicolumn{4}{c}{$A D C$} \\
\cline { 2 - 5 } & MS & PB & FDN & EB \\
& $D M$ & $C P$ & $N D F$ & $G E$ \\
\hline $165,28 \mathrm{a}$ & $67,75 \mathrm{a}$ & $63,05 \mathrm{a}$ & $65,33 \mathrm{a}$ & \\
$263,71 \mathrm{a}$ & $65,35 \mathrm{a}$ & $51,59 \mathrm{a}$ & $62,97 \mathrm{a}$ & \\
$362,16 \mathrm{a}$ & $62,88 \mathrm{a}$ & $51,56 \mathrm{a}$ & $61,71 \mathrm{a}$ & \\
$463,82 \mathrm{a}$ & $63,72 \mathrm{a}$ & $49,83 \mathrm{a}$ & $62,58 \mathrm{a}$ & \\
\hline
\end{tabular}

${ }^{1}$ Médias seguidas de mesma letra, na coluna, não diferem pelo teste Newman Keuls.

2 Tratamento: 1 = volumoso aos 4 dias e desmama aos 56 dias de idade; 2 = volumoso aos 60 dias e desmama aos 56 dias de idade; 3 = volumoso aos 4 dias e desmama aos 35 dias de idade; $4=$ volumoso aos 60 dias e desmama aos 35 dias de idade.

${ }^{1}$ Means followed by the same letter, in a column, do not differ by Newman Keuls test.

2 Treatment: $1=$ roughage at $4^{\text {th }}$ day and weaning at the $56^{\text {th }}$ day of age; $2=$ roughage at $60^{\text {th }}$ day and weaning at the $56^{\text {th }}$ day of age; $3=$ roughage at $4^{\text {th }}$ day and weaning at the $35^{\text {th }}$ day of age; $4=$ roughage at $60^{\text {th }}$ day and weaning at the $35^{\text {th }}$ day of age.

digestibilidade aparente da MS, PB, FDN e EB.

Não houve influência dos tratamentos, a que os bezerros foram submetidos, no período de aleitamento, sobre o consumo e os coeficientes de digestibilidade aparente da MS, PB, FDN e EM, no período de 72 a 78 dias de idade. Os animais que receberam volumoso a partir dos quatro dias de idade e foram desmamados aos 56 dias (tratamento 1) apresentaram valores numéricos mais elevados para todos os coeficientes de digestibilidade aparente determinados.

Provavelmente, a idade dos animais ao início do ensaio (72 dias) pode ter contribuído para a pequena diferença verificada nos CDap, pois, segundo FUNABA et al. (1994), ocorre aumento compensatório da digestibilidade da MS após a desmama, desaparecendo, rapidamente, diferenças na digestibilidade de nutrientes, devidoaomenor desenvolvimento inicial do trato digestivo.

Os coeficientes de digestibilidade são altamente influenciados pela natureza da dieta. Os valores observados neste experimento estão dentro de limites observados em pesquisas no Brasil, sendo inferiores aos relatados por PIMENTEL e PEIXOTO (1983), que encontraram CDap da proteína de 72,73; 73,89 e $74,84 \%$ e da matéria seca de 73,$03 ; 71,75$ e $72,31 \%$, para bezerros jovens consumindo rações contendo, respectivamente, 0,25 e $50 \%$ de farelo de arroz. Para a
Tabela 4 - Balanço diário de nitrogênio dos bezerros, de acordo com o tratamento prévio

Table 4 - Daily nitrogen balance of calves according to previous treatments

\begin{tabular}{|c|c|c|}
\hline \multirow[t]{2}{*}{$\begin{array}{l}\text { Tratamento } \\
\text { Treatment }\end{array}$} & \multicolumn{2}{|c|}{$\begin{array}{c}\mathrm{N} \text { retido } \\
N \text { retained }\end{array}$} \\
\hline & $\begin{array}{l}\text { g/dia } \\
\text { g/day }\end{array}$ & $\begin{array}{c}\mathrm{g} / \mathrm{kg}^{0,75} / \mathrm{dia} \\
\mathrm{g} / \mathrm{kg}^{.75} / \mathrm{day}\end{array}$ \\
\hline 1 & $14,83 \mathrm{a}$ & $0,71 \mathrm{a}$ \\
\hline$z$ & & \\
\hline & $15,45 \mathrm{a}$ & $0,73 a$ \\
\hline & $14,72 \mathrm{a}$ & $0,74 \mathrm{a}$ \\
\hline \multirow{2}{*}{\multicolumn{3}{|c|}{$\begin{array}{l}{ }^{1} \text { Médias seguidas de mesma letra, na coluna, não diferem pelo teste } \\
\text { Newman Keuls. } \\
2 \text { Tratamento: } 1=\text { volumoso aos } 4 \text { dias e desmama aos } 56 \text { dias de } \\
\text { idade; } 2 \text { = volumoso aos } 60 \text { dias e desmama aos } 56 \text { dias de idade; } \\
3=\text { volumoso aos } 4 \text { dias e desmama aos } 35 \text { dias de idade; } 4= \\
\text { volumoso aos } 60 \text { dias e desmama aos } 35 \text { dias de idade. } \\
1 \text { Meansfollowed by the same letter, in a column, do not differby Newman Keuls } \\
\text { test. }\end{array}$}} \\
\hline & & \\
\hline \multicolumn{3}{|c|}{$\begin{array}{l}2 \text { Treatment: } 1=\text { roughage at } 4^{\text {th }} \text { day and weaning at the } 56^{\text {th }} \text { day of age; } 2= \\
\text { roughage at } 60^{\text {th }} \text { day and weaning at the } 56^{\text {th }} \text { day of age; } 3=\text { roughage at } 4^{\text {th }} \\
\text { day and weaning at the } 35^{\text {th }} \text { day of age; } 4=\text { roughage at } 60^{\text {th }} \text { day and weaning } \\
\text { at the } 35^{\text {th }} \text { day of age. }\end{array}$} \\
\hline
\end{tabular}

digestibilidade da matéria seca, os valores observados são, entretanto, superiores ao valor médio de 58,6\% observado por VALADARES FILHO (1985), para ração contendo $60 \%$ de concentrado e $40 \%$ de feno de capim-gordura, em bovinos de cinco grupos genéticos e bubalinos, com idade média de 16 meses.

A Tabela 4 mostra as médias de quadrados mínimos para balanço de nitrogênio dos bezerros, de 72 a 78 dias de idade.

Não foram verificadas diferenças entre tratamentos quanto ao balanço de nitrogênio, expressos em $\mathrm{g} / \mathrm{dia}$ e $\mathrm{g} / \mathrm{kg}^{0,75} / \mathrm{dia}$.

Valores de balanço de nitrogênio, em bezerros, mais elevados que os observados neste experimento foram relatados por FUNABA et al. (1994). Entretanto, os valores encontrados refletem níveis de acúmulo de proteína corporal compatíveis com os ganhos de peso que foram observados nos animais na fase anterior ao presente ensaio.

De modo geral, não há evidência de terem ocorrido diferenças fisiológicas persistentes, quanto ao desenvolvimento ruminal dos bezerros, por influência da idade ao início do fornecimento de capim-napier e da desmama, conforme indica a ausência de diferenças nos coeficientes de digestibilidade e balanço de nitrogênio, entre tratamentos. 


\section{Conclusões}

As idades ao início de fornecimento de volumoso (4 ou 60 dias) e de desmama (35 ou 56 dias) não influenciaram significativamente os coeficientes de digestibilidade aparente da MS, PB, FDN e EB e balanço de nitrogênio, quando medidos na terceira semana após a desmama dos bezerros.

\section{Referências Bibliográficas}

ANDERSON, K.L., NAGARAJA, T.G., MORRILL, J.L. et al. Ruminal microbial development in conventionally or earlyweaned calves. J. Anim. Sci., 64(4):1215-26, 1987a.

ANDERSON, K.L., NAGARAJA, T.G., MORRILL, J.L. Ruminal metabolic development in calves weaned conventionally or early. J. Dairy Sci., 70(5):1000-1005, 1987b.

BLAXTER, K.L., HUTCHESON, M.K., ROBERTSON, J.M. et al. The influence of diet on the development of the alimentary tract of the calf. Br. J. Nut., 6(1):68-75, 1952.

FUNABA, M., KAGIYAMA, K., IRIKI, T. et al. Changes nitrogen balance with age in calves weaned at 5 or 6 weeks of age. J. Anim. Sci., 72(3):732-8, 1994.

HARVEY, W.R. Mixed model least squares and maximum likelihood computer program (LSMLMW), versão PC-1, 1990.

LUCCI, C.S. Aspectos principais da alimentação de bezerros. Zootecnia, 14(1):15-27, 1976.
MISRA, A.K., MEHRA, U.R. Performance of crossbred calves reared on two regimens of milk feeding. Ind. J. Dairy Sci., 46(12):588-91, 1993.

OTTERBY, D.E., LINN, J.G. Advances in nutrition and management of calves and heifers. J. Dairy Sci., 64(6):136577, 1981.

PIMENTEL, M.A., PEIXOTO, R.R. Desaleitamento precoce de terneiro. 2. Valor do farelo de arroz em rações. R. Soc. Bras. Zootec., 12(4):654-66, 1983.

TAMATE, H., McGILliARD, A.D., JACOBSON, N.L. et al. Effect of various dietaries on the anatomical development of the stomach in the calf. J. Dairy Sci., 45(2):408-20, 1962.

VALADARES FILHO. S.C. Digestão parcial da matéria seca e carboidratos em bovinos e bubalinos. Viçosa, MG: UFV, 1985, 148p. Tese (Doutorado em Zootecnia) - Universidade Federal de Viçosa, 1985.

WILLIAMS, P.E.V., INNES, G.M., BREWER, A. et al. The effects on growth, food intake and rumen volume of including untreated or ammonia-treated barley straw in a complete diet for weaning calves. J. Dairy Sci., 41(1):63-74, 1985.

Recebido em: 25/06/97

Aceito em: 27/08/98 